\title{
Detailed Echocardıographıc Assessment in Asthmatıc Patıents
}

\author{
Duygu Zorluํㅜ, Yalçın Boduroğlu ${ }^{2}$, and Arzu Ertürk ${ }^{1}$ \\ ${ }^{1}$ Ahi Evran University Faculty of Medicine \\ ${ }^{2}$ Ahi Evran Universitesi Tip Fakultesi
}

January 7, 2021

\begin{abstract}
Introduction:It has been known that there is a complex interaction between asthma and cardiovascular physiology.Some investigations on echocardiography and electrocardiography(ECG) in asthmatic patients revealed many findings such as pulmonary hypertension(PHT) and arrhythmia.In this study, we aimed to perform tissue doppler imaging(TDIE) and conventional echocardiographic(CEI) assessment with many indexes of arrhythmia on electrocardiography(ECG) in asthmatic patients.Methods:A total of 89 patients, 63 female(70.8\%) and 26 male(29.2\%), was included in this study.Patients were divided into three groups and then each group was separated in two 2 groups as mild-moderate and severe asthma.Results:There is no difference among groups with respect to age,gender and anthropometric data and no difference between groups with respect to indexes of arrhythmia on ECG(p $>0.05)$.It was determined that ventricular outflow systolic velocity recordings at aortic and pulmonary valve were similar(p>0.05).MAPSE,TAPSE and both ventricular diastolic velocities on CEI were similar between groups, except for left ventricular A wave velocity which was higher in severe asthmatic patients $(\mathrm{p}<0.05)$. No difference between groups was detected in left atrium(LA) TDIE diastolic velocities $(\mathrm{p}>0.05)$.Investigation of time intervals of both ventricular diastolic filling velocities(e' and a') at the mitral lateral,septal and tricuspid lateral annulus revealed significant difference at Pa'm- 3 and Pa's- 3 intervals based on $\operatorname{TDEI}(\mathrm{p}<0.05)$.Investigation of the LA volumes determined that only maximal volume of the LA was higher in severe asthmatic patients $(\mathrm{p}<0.05)$. However, there is no significant difference between LA-VpreA and LA-Vmin $(\mathrm{p}>0.05)$.Conclusions:Based on these results, it can be suggested that LA mechanical functions and intra-atrial LA electromechanical durations were impaired in severe asthmatic patients.
\end{abstract}

\section{Abstract}

Introduction: It has been known that there is a complex interaction between asthma and cardiovascular physiology. Some investigations on echocardiography and electrocardiography (ECG) in asthmatic patients revealed many findings such as pulmonary hypertension (PHT) and arrhythmia. In this study, we aimed to perform tissue doppler imaging (TDIE) and conventional echocardiographic (CEI) assessment with many indexes of arrhythmia on electrocardiography (ECG) in asthmatic patients.

Methods: A total of 89 patients, 63 female (70.8\%) and 26 male (29.2\%), was included in this study. Patients were divided into three groups, and then each group was separated in two 2 groups as mild-moderate and severe asthma.

Results: There is no difference among groups with respect to age, gender and anthropometric data and no difference between groups with respect to indexes of arrhythmia on ECG ( $p>0.05$ ). It was determined that ventricular outflow systolic velocity recordings at aortic and pulmonary valve were similar $(\mathrm{p}>0.05)$. MAPSE, TAPSE and both ventricular diastolic velocities on CEI were similar between groups, except for left ventricular A wave velocity which was higher in severe asthmatic patients $(\mathrm{p}<0.05)$. No difference between groups was detected in left atrium (LA) TDIE diastolic velocities $(\mathrm{P}>0.05)$. Investigation of time intervals of both ventricular diastolic filling velocities (e' and a') at the mitral lateral, septal and tricuspid lateral annulus revealed significant difference at Pa'm- 3 and Pa's- 3 intervals based on TDEI $(\mathrm{p}<0.05)$. Investigation of the 
LA volumes determined that only maximal volume of the LA was higher in severe asthmatic patients $(\mathrm{p}<$ 0.05). However, there is no significant difference between LA-VpreA and LA-Vmin ( $p>0.05)$.

Conclusions: Based on these results, it can be suggested that LA mechanical functions and intra-atrial LA electromechanical durations were impaired in severe asthmatic patients.

Keywords: Electromechanical Conduction Delay, Atrial Volume, Asthma

\section{Hosted file}

Manuscript (2).pdf available at https://authorea.com/users/388020/articles/502878-detailedechocard $\%$ C4\%B1ograph $\%$ C4\%B1c-assessment-in-asthmat $\%$ C4\%B1c-pat $\%$ C4 $\%$ B1ents

\section{Hosted file}

Figures (2).pdf available at https://authorea.com/users/388020/articles/502878-detailedechocard $\%$ C4\%B1ograph $\%$ C4\%B1c-assessment-in-asthmat $\%$ C4\%B1c-pat $\%$ C4\%B1ents 